\title{
O PROGRAMA ENSINO MÉDIO INOVADOR (PROEMI): OLHARES DOS PESQUISADORES (2009-2019)
}

\author{
Maria do Amparo Oliveira Brito* \\ Etelvina de Queiroz Santos*
}

\section{RESUMO}

O presente trabalho apresenta as vozes de pesquisadores sobre o programa ensino médio inovador (PROEMI) publicadas no período de 2009 a 2019. Transcorridos mais de 10 anos da criação do GT Interministerial que elaborou o documento "Reestruturação e Expansão do Ensino Médio no Brasil, que além de mapear os desafios vivenciados pela Educação Básica no país e em especial o Ensino Médio, propõe elementos e pressupostos para uma política para essa modalidade de ensino, que visa atender aos jovens na faixa etária ente os 15 e 17 anos, buscamos compreender e conhecer aquilo que está sendo produzido no campo científico sobre o PROMI e o que ainda não foi abordado e que precisa ser discutido, tendo em vista o delineamento de novas investigações a respeito da referida temática. Para tanto, realizamos um levantamento de produções acadêmicas, dissertações e teses. Este levantamento das produções sobre o PROMI possibilitou-nos conhecer o que tem sido discutido e analisado sobre a temática, e, orientou-nos quanto às análises que ainda precisam ser feitas para contribuir com a ampliação dos conhecimentos sobre esse campo da ciência.

Palavras-chave: PROEMI. Educação Integral. Recontextualização. Currículo. Políticas Públicas.

\footnotetext{
${ }^{*}$ Mestranda em Educação pela Facultad Interamericana de Ciencias Sociales. Asunción-PY. Contatos: Email: amparocba@yahoo.com (77) 98115-4741

* Mestre em Educação pelo Programa de Pós-graduação em Educação da Universidade Estadual do Sudoeste da Bahia - PPGED/UESB. Contatos:E-mail: vik714@ hotmail.com 77981402819
} 


\section{INTRODUÇÃO}

Com o intento de justificar e ressaltar a importância desse estudo realizamos um levantamento de pesquisas sobre o PROEMI, a fim de conhecer o que tem sido discutido e analisado sobre o tema nas produções acadêmicas especificamente, dissertações e teses já defendidas.

O PROEMI se apresenta como estratégia do MEC para melhorar a qualidade do Ensino Médio por meio da dinamização e flexibilização do currículo. O programa possui oito macrocampos e o presente estudo está vinculado a importância deste programa para a concretização da Educação Integral em uma escola Estadual do sudoeste da Bahia.

A Secretaria de Educação Básica do Ministério da Educação no ano de 2009 propôs uma concepção diferenciada de organização pedagógico-curricular para a última etapa da educação básica. O Programa Ensino Médio Inovador (PROEMI), criado pela Portaria n. 971, de 9 de outubro de 2009 (BRASIL, 2009a), se apresenta como estratégia do MEC para a melhoria da qualidade do Ensino Médio nas escolas públicas

A iniciativa faz parte das ações do Plano de Desenvolvimento da Educação (BRASIL, 2007), e está pautada na necessidade de proporcionar aos estudantes situações de aprendizado significativas, aproximando a escola dos interesses e da cultura juvenil. O objetivo apresentado no PROEMI é incentivar a criação de novas propostas curriculares para garantir a ampliação do tempo dos estudantes na escola, além de proporcionar uma formação integral, com a inclusão de atividades que tornem o currículo mais dinâmico.

Nesse sentido, realizamos um levantamento das produções acadêmicas, dissertações e teses, sobre o PROEMI. Este trabalho possibilitou conhecer aquilo que está sendo produzido no campo científico e o que ainda não foi abordado e que precisa ser discutido, tendo em vista o delineamento de novas investigações a respeito da referida temática.

Este diagnóstico foi realizado no mês de fevereiro de 2019 e início de abril, no Banco de Teses e Dissertações da Coordenação de Aperfeiçoamento de Pessoal de Nível Superior (CAPES).

Foram encontrados inúmeros trabalhos que abordam o PROEMI em vários aspectos. No entanto, o que nos interessa aqui são as produções que discutem as a importância do programa para a concretização do Ensino Integral. 
Tendo em vista que o nosso objeto é compreender o Ensino Médio Inovador como programa indutor da implantação da educação integral e sua recontextualização em um colégio estadual da Bahia, utilizamos o descritor PROEMI, a fim de filtrar a busca e aproximá-la do tema da pesquisa.

\section{O PROGRAMA ENSINO MÉDIO INOVADOR (PROEMI): OLHARES DOS PESQUISADORES (2009-2019)}

Para realização deste trabalho elecionamos 93 dissertações e teses, realizamos a leitura de todos os resumos destas e escolhemos as produções que continham as informações com maior proximidade ao nosso objeto. Desse modo, foram selecionados os trabalhos que apresentavam as seguintes palavras-chave: PROEMI, Educação Integral, Políticas Publicas.

Neste sentido, apresentamos no quadro abaixo uma pequena amostra das pesquisas realizadas e suas características.

Quadro I - Teses e Dissertações que versam sobre o PROEMI

\begin{tabular}{|l|l|l|l|}
\hline Ano & \multicolumn{1}{|c|}{ Titulo Autor/a } & \multicolumn{1}{|c|}{ Instituição } \\
\hline 2015 & $\begin{array}{l}\text { Uma experiência do programa } \\
\text { ensino médio inovador em } \\
\text { Ananindeua - Pará }\end{array}$ & $\begin{array}{l}\text { Maria Rosana } \\
\text { de Oliveira } \\
\text { Castro }\end{array}$ & UFPA \\
\hline 2018 & $\begin{array}{l}\text { Expressões concretas do } \\
\text { programa ensino médio } \\
\text { inovador (PROEMI) nas } \\
\text { escolas públicas estaduais da } \\
\text { mata sul de Pernambuco das }\end{array}$ & $\begin{array}{l}\text { Maria } \\
\text { Graças } \\
\text { Correia } \\
\text { Gomes }\end{array}$ & TESE \\
\hline 2017 & $\begin{array}{l}\text { A Educação Integral e o } \\
\text { Programa Ensino Médio } \\
\text { Inovador - Proemi: } \\
\text { singularidades desta política } \\
\text { em uma escola estadual }\end{array}$ & $\begin{array}{l}\text { Tânia Castro } \\
\text { Gomes }\end{array}$ & UFOPA \\
\hline
\end{tabular}




\begin{tabular}{|c|c|c|c|}
\hline 2016 & $\begin{array}{l}\text { O Programa Ensino Médio } \\
\text { Inovador (PROEMI) e a } \\
\text { formação política de jovens na } \\
\text { escola pública }\end{array}$ & $\begin{array}{l}\text { Sandra } \\
\text { Cristina } \\
\text { Andrade } \\
\text { Almeida } \\
\text { Gomes }\end{array}$ & $\begin{array}{l}\text { UNB } \\
\text { DISSERTAÇÃO }\end{array}$ \\
\hline 2017 & $\begin{array}{l}\text { Redesenho curricular no } \\
\text { programa ensino médio } \\
\text { inovador: recontextualizações } \\
\text { da política }\end{array}$ & $\begin{array}{l}\text { Ricardo } \\
\text { Inocêncio } \\
\text { Pereira }\end{array}$ & $\begin{array}{l}\text { FURB } \\
\text { DISSERTAÇÃO }\end{array}$ \\
\hline 2014 & $\begin{array}{l}\text { Curso de Formação "Gestão } \\
\text { Escolar para Resultados": Uma } \\
\text { Análise à Luz da Experiência } \\
\text { da Implementação do } \\
\text { Programa Ensino Médio } \\
\text { Inovador em Conjunto com o } \\
\text { Projeto Jovem de Futuro }\end{array}$ & $\begin{array}{l}\text { Elizabete } \\
\text { Santos } \\
\text { Mofacto }\end{array}$ & $\begin{array}{l}\text { UFJF } \\
\text { DISSERTAÇÃO }\end{array}$ \\
\hline 2015 & $\begin{array}{l}\text { Programa Ensino Médio } \\
\text { Inovador - ProEMI: o que } \\
\text { revelam as intenções de } \\
\text { melhoria do ensino médio no } \\
\text { Brasil - o caso do Distrito } \\
\text { Federal }\end{array}$ & $\begin{array}{l}\text { Kattia de } \\
\text { Jesus Amin } \\
\text { Athayde } \\
\text { Figueiredo }\end{array}$ & $\begin{array}{l}\text { UNB } \\
\text { TESE }\end{array}$ \\
\hline 2015 & $\begin{array}{l}\text { Programa Ensino Médio } \\
\text { Inovador no Espírito Santo: } \\
\text { Mudança ou Continuidade nas } \\
\text { Políticas do Ensino Médio. }\end{array}$ & $\begin{array}{l}\text { Claudia de } \\
\text { Souza } \\
\text { Nardoto }\end{array}$ & $\begin{array}{l}\text { UFJF } \\
\text { DISSERTAÇÃO }\end{array}$ \\
\hline 2015 & $\begin{array}{l}\text { Análise do Programa Ensino } \\
\text { Médio Inovador no Estado do } \\
\text { Amapá no Período de } 2010 \text { a } \\
2014 \text {. }\end{array}$ & $\begin{array}{l}\text { Wanda Mara } \\
\text { Meguins } \\
\text { Matos }\end{array}$ & $\begin{array}{l}\text { UFPA } \\
\text { DISSERTAÇÃO }\end{array}$ \\
\hline 2016 & $\begin{array}{l}\text { O Programa Ensino Médio } \\
\text { Inovador (Proemi) na Rede } \\
\text { Estadual de Ensino de Mato } \\
\text { Grosso do Sul (2007-2011). }\end{array}$ & $\begin{array}{l}\text { Waneide } \\
\text { Ferreira dos } \\
\text { Santos }\end{array}$ & $\begin{array}{l}\text { UCDB } \\
\text { DISSERTAÇÃO }\end{array}$ \\
\hline
\end{tabular}

Fonte: Elaboração da autora 2019

Apresentaremos aqui uma síntese das dissertações e teses que subsidiam este trabalho. 
A Tese "Uma experiência do Programa Ensino Médio Inovador em Ananindeua - Pará" é resultado dos estudos de doutoramento que teve como objetivo analisar o processo de implementação do PROEMI na Escola Estadual de Ensino Fundamental e Médio Prof. Antônio Gondim Lins, em Ananindeua-Pará, no período de 2009 a 2015, especialmente no que se refere à gestão escolar e à melhoria dos resultados da aprendizagem dos estudantes.

O texto faz uma discussão a respeito do papel do Estado diante das parcerias público-privadas em seus processos de regulação e implantação e sobre a crise estrutural do capital que resultou na redefinição do papel do Estado, que transferiu os serviços públicos considerados essenciais a setores privados. Discute ainda os conceitos de público e privado, destacando as parcerias público-privadas na educação do Brasil e no Pará.

O trabalho apresenta a política nacional para o Ensino Médio no Brasil, com dados sobre esse nível de ensino e contextualizando-o no quadro da legislação educacional em vigor aproximando-se a estudiosos da área que defendem esse nível de ensino integrado com todas as dimensões da vida.

Discute-se também o processo de implementação do PROEMI na Escola Estadual de Ensino Fundamental e Médio Prof. Antônio Gondim Lins, revelando o desconhecimento da comunidade escolar sobre o Programa, indicando que ele não foi discutido na escola e que a SEDUC -PA não cumpriu seu papel na garantia de condições adequadas para implementação do PROEMI que, apesar de ter destinado e a escola ter recebido, em duas ocasiões recursos do Programa, sua aplicação foi empregada de forma indevida.

A tese Expressões concretas do programa ensino médio inovador (PROEMI) nas escolas públicas estaduais da mata sul de Pernambuco, buscou investigar quais as transformações ocorridas nas escolas com a implementação do Programa.

No campo teórico metodológico dialogou-se a respeito das políticas públicas da educação relacionada com uma ação pública em um contexto de relações de poder na qual um programa significa sua materialização para dar visibilidade ao Estado, o Estado em ação.

No metodológico, a abordagem qualitativa proporcionou compreender como as pessoas experimentam, entendem, interpretam e participam de seu mundo social e 
cultural. A utilização do método dialético permitiu a produção de um conhecimento da realidade concreta, seus movimentos e as relações internas no que se referem ao social, econômico e político.

Os resultados revelaram que a Secretaria de Educação do Estado de Pernambuco não construiu nenhuma proposta para integrar o Programa Ensino Médio Inovador ao Programa de Educação Integral. Coube à escola a responsabilidade de implementá-lo. A adesão ao programa ocorreu diante da possibilidade de acesso aos recursos oriundos do governo federal para as escolas que o adotassem. Inexistiu assistência técnico pedagógica acerca dos pressupostos teóricos do programa, a preocupação maior era com o cumprimento das metas por meio da gestão de resultados.

Apesar de o PROEMI não ter conseguido atingir seus objetivos, a escola planejou ações que modificaram o cotidiano escolar, o professorado propôs atividades diferentes do que ocorria habitualmente e o alunado se mostrou interessado quando havia momentos diferenciados das aulas regulares. Desse modo, comprovando-se que o programa provocou transformações na a escola pública.

A dissertação, A Educação Integral e o Programa Ensino Médio Inovador Proemi: singularidades desta política em uma escola estadual, defendida em 2017 na UFOPA, têm por objetivo analisar o Programa Ensino Médio Inovador - PROEMI implementado em uma escola estadual em Santarém-Pará, no período de 2012 a 2014. Este período justifica-se por corresponder ao ano de implantação (2012), na cidade, e desenvolvimento do primeiro ciclo das atividades concernentes ao programa, que condizem aos três anos (2012, 2013 e 2014).

A investigação foi desenvolvida por meio do estudo de caso realizado em uma unidade escolar do município de Santarém/Pará. Envolveu técnicas padronizadas de coleta de dados, como entrevista semiestruturada e, na discussão dos resultados, utilizou a análise de conteúdo (BARDIN, 2011), com base nas evidências agrupadas por categorias.

As categorias elencadas foram: conceito de educação integral e ações pedagógicas no PROEMI. Com relação aos resultados da pesquisa foram identificadas disparidades entre a concepção de educação integral e educação em tempo integral na escola estudada. 
Sobre as ações pedagógicas desenvolvidas no PROEMI, observou-se, na investigação, que as orientações sobre a efetivação do programa não condizem com realidade encontrada na implantação no que se refere ao assessoramento técnico, pedagógico e financeiro; à garantia de execução dos projetos originados na demanda da comunidade escolar; à obrigatoriedade em compreender a coexistência do PROEMI e PJF em suas concepções e metodologias distintas; e à necessidade de organização pedagógica da escola em turno parcial para atender propostas de um currículo interdisciplinar.

A dissertação O Programa Ensino Médio Inovador (PROEMI) e a formação política de jovens na escola pública, defendida em 2016 na UNB, teve como objetivo investigar as percepções dos estudantes em relação às potencialidades do Programa Ensino Médio Inovador (PROEMI) na formação política dos jovens em uma escola pública do Distrito Federal.

Os dados desta investigação foram coletados por meio de questionários aplicados em duas turmas e um grupo focal com cinco integrantes do grêmio estudantil. A análise foi realizada a partir do programa Alceste. Um total de 62 estudantes participou da pesquisa. Para a discussão de educação política, movimentos sociais e grêmio estudantil, os principais teóricos estudados foram Freire, Gohn, Dayrell, Melucci, dentre outros.

O estudo revelou que o grêmio se constitui como espaço de aprendizagem, seja no contexto da cidadania ou da política, e contribui no fortalecimento da gestão escolar. Embora sua existência esteja legitimada, dificuldades foram apontadas em seu reconhecimento e organização. Os estudantes encontram dificuldades no fortalecimento da entidade e carecem de apoio teórico e organizacional.

A autora concluiu que mesmo com a participação no Programa, as percepções apresentadas pelos estudantes demonstraram que a escola parece não conseguir dar o apoio necessário à participação estudantil e, portanto, não ter atingido a proposta do PROEMI no macrocampo pesquisado.

A dissertação Redesenho curricular no programa ensino médio inovador: recontextualizações da política defendida no ano de 2017 na Universidade Regional de Blumenau (FURB) propõe um olhar voltado para a realidade do Ensino Médio (EM) no Brasil e realiza um debate histórico em torno de sua identidade. 
Além disso, discute sobre o Programa Ensino Médio Inovador (PROEMI), que enfatiza a integração entre as áreas, a contextualização do conhecimento e a ampliação da jornada escolar. Considerando que as políticas educacionais passam por recontextualizações desde as influências na produção do Discurso Pedagógico Oficial (DPO) até a atuação no contexto da prática, esta dissertação busca compreender como a política de redesenho curricular do PROEMI é recontextualizada do macro ao microcontexto.

Os objetivos específicos são: reconhecer o contexto de influência no DPO do PROEMI sobre redesenho curricular; identificar e problematizar, a partir dos textos das políticas oficiais do PROEMI, princípios e estratégias para o redesenho curricular; analisar a "atuação da política" de redesenho curricular do PROEMI no contexto da prática.

Argumenta-se, com base nos resultados, que o PROEMI é uma política de redesenho curricular ampla, complexa e inovadora. Porém, mesmo com tantos desafios, evidenciados por tensões nas diferentes dimensões contextuais, os profissionais acreditam na política. Apesar disso, interpretam dela apenas fragmentos.

A dissertação Curso de Formação “Gestão Escolar para Resultados”: Uma Análise à Luz da Experiência da Implementação do Programa Ensino Médio Inovador em Conjunto com o Projeto Jovem de Futuro, Mofacto (2014), analisa a implementação do PROEMI, criado pelo Ministério da Educação em conjunto com o Projeto Jovem do Futuro (PJF) de iniciativa do Instituto UNIBANCO, com o foco na experiência de formação dos supervisores das secretarias de estado de educação de dois estados brasileiros que implementaram o PEMI/PJF.

A metodologia baseou-se na aplicação de questionários aos supervisores, coordenadores do PROEMI/PJF e gestores locais do Instituto Unibanco nos dois estados que iniciaram o programa em 2011, Mato Grosso do Sul e Ceará. Os resultados identificaram elementos relevantes para a construção de uma proposta de intervenção efetiva, e consistiram em recomendações para a melhoria dos resultados do Curso de Formação em Gestão Escolar destinado aos supervisores do ProEMI/PJF.

A Tese Programa Ensino Médio Inovador - PROEMI: o que revelam as intenções de melhoria do ensino médio no Brasil - o caso do Distrito Federal apresentada por 
Figueiredo (2015) vários objetivos foram investigados e verificou se a proposta de Resenho Curricular implicou mudanças significativas na escola; além disso, analisou a percepção dos gestores, coordenadores, professores e estudantes sobre o reconhecimento do PROEMI como Programa promotor de inovações na escola.

Também analisou se o PROEMI melhorou os indicadores de evasão e de repetência nas escolas públicas do DF, verificou se os macrocampos postulados pelos Documentos Orientadores do Programa estão em harmonia com a Proposta de Redesenho Curricular das escolas de Ensino Médio do DF que aderiram ao PROEMI.

Os resultados apresentaram que: a inovação na educação é tratada como um ganho de valor considerável para práticas pedagógicas, uma vez que favorece o desenvolvimento da autonomia entre professores, gestores e estudantes incidindo na reorganização do trabalho pedagógico das escolas.

Infere-se que a proposta de Redesenho Curricular compõe um cenário atrativo de fomentos pedagógicos para o Ensino Médio, percebido na conexão dos macrocampos com as áreas de conhecimento e os componentes curriculares em sua inter-relação com as vivências sociais dos estudantes.

Na dissertação Programa Ensino Médio Inovador no Espírito Santo: Mudança ou Continuidade nas Políticas do Ensino Médio, Nardoto (2015) analisa a implantação do PROEMI na rede estadual do Espírito Santo.

O autor centrou seus objetivos em estudar os critérios utilizados para adesão e implementação do PROEMI pela secretaria de educação do Espírito Santo e a análise dos Projetos de Redesenho Curricular (PRC) elaborados pelas unidades escolares nos anos 2013/2014 da Região Metropolitana, a fim de verificar as possibilidades de melhoria do ensino médio a partir dessa política de governo.

O trabalho apresenta três capítulos nos quais apresenta: pesquisas sobre o Ensino Médio no Brasil; análise do PROEMI como política de reestruturação curricular e sua implantação no Espírito Santo e a organização dos Projetos de Redesenho Curricular elaborados pelas escolas.

Na dissertação Análise do Programa Ensino Médio Inovador no Estado do Amapá no Período de 2010 a 2014, Matos (2015) analisa a experimentação do Programa Ensino Médio Inovador no estado do Amapá, sobretudo, sua relação com a dinâmica curricular à luz do conceito de Inovação orientado pela ideia de integração. 
Estabelece como procedimento metodológico a pesquisa documental, precedida de revisão bibliográfica, baseada na perspectiva crítico dialética, com análise das propostas curriculares que orientaram o programa em uma das oito escolas que iniciaram sua experimentação no Amapá a partir do ano de 2010, bem como o monitoramento do rendimento e movimento dos primeiros alunos que cursaram o ensino médio neste estado no período de 2010 a 2012.

Concluiu-se que, com o programa, a escola passou a orientar-se com dois currículos, um disciplinar e outro não, mas com um foco em comum: a preparação para o ENEM, que reforça a fragmentação curricular e a predominância do caráter preparatório do Ensino Médio mesmo com propostas alternativas inovadoras.

A dissertação O Programa Ensino Médio Inovador (Proemi) na Rede Estadual de Ensino de Mato Grosso do Sul (2007-2011), Santos (2016) apresenta o Programa Ensino Médio Inovador (PROEMI), na Rede Estadual de Ensino do Estado de Mato Grosso do Sul, no recorte temporal de 2007 a 2011, que se justifica por ser 2007 o ano lançamento do Plano de Desenvolvimento da Educação (PDE) e do Plano de Metas Compromisso Todos pela Educação, e 2011 o ano da parceria firmada entre o governo do Estado do Mato Grosso do Sul e o Instituto Unibanco que deu origem ao PROEMI/Jovem do Futuro.

Teve como objetivo geral analisar o processo de implantação e implementação do PROEMI em duas escolas localizadas em Campo Grande MS. Como procedimentos metodológicos foram utilizados a pesquisa bibliográfica e a documental, além de entrevistas baseadas em questões semiestruturadas.

Os resultados permitem afirmar que no Estado de Mato Grosso do Sul, as escolas selecionadas encontraram dificuldades na implementação do PROEMI em razão da estrutura física inadequada, da falta de professores e de profissionais de apoio escolar capacitados, do atraso dos recursos financeiros do programa, entre outros.

Após a análise das produções apresentadas ficou evidente a importância do nosso estudo visto que os trabalhos até então produzidos, realizaram análise do PROEMI nos diversos contextos, contudo, não encontramos trabalhos que façam a interseção entre a educação integral e o Programa Ensino Médio Inovador. 


\section{CONCLUSÃO}

Os trabalhos selecionados contribuíram de forma específica para compreendermos como a temática vem sendo debatida ao longo dos anos no campo acadêmico. A leitura das teses e dissertações possibilitou perceber que existem muitas publicações sobre a educação integral no Brasil, contudo, ainda é ínfimo os trabalhos que discutem a recontextualização e redesenho curricular proporcionado pelo PROMI

O levantamento das produções possibilitou-nos conhecer o que tem sido discutido e analisado sobre a temática, e, orientou-nos quanto às análises que ainda precisam ser feitas para contribuir com a ampliação dos conhecimentos sobre esse campo de pesquisa.

Percebemos que as pesquisas são recentes, apesar da legislação estar em vigor desde 2009; as maiores produções foram construídas a partir de 2013, além disso, observamos que a maioria dos trabalhos está voltada para a questão da educação integral. Isso sinaliza a relevância da nossa pesquisa e e orientou-nos quanto às análises que ainda precisam ser feitas para contribuir com a ampliação dos conhecimentos sobre esse campo de pesquisa

\section{REFERENCIAS}

BRASIL. MEC/SEB. Reestruturação e Expansão do Ensino Médio no Brasil. Versão preliminar. Brasília, DF, jul,2008. Disponível em:http://portal.mec.gov.br/seb/arquivos/pdf/2009/gt_interministerialresumo2.pf. Acesso em: 01/05/2018.

.Ministério da Educação (MEC). Secretaria de Educação Continuada, Alfabetização e Diversidade (Secad). Programa Mais Educação: gestão intersetorial no território. Brasília, 2009b. Disponível em: http://portal.mec.gov.br/dmdocuments/cader_maiseducacao.pdf.Acesso em: 10.jan.2019

.Ministério da Educação e Cultura - Portaria n 971, de 09 de outubro de 2009 http://portal.mec.gov.br/docman/documentos-pdf/1634-port-971/file Acesso em: 01/05/2018.

Programa Ensino Médio Inovador. Documento Orientador. Brasília: Ministério da Educação, 2014a. 
CASTRO, Maria Rosana de Oliveira. Uma experiência do programa ensino médio inovador em Ananindeua. Tese. Belém, 2017.

FERREIRA, Michele Guerreiro. Sentidos da educação das relações étnico-raciais nas práticas curriculares de professore(a)s de escolas localizadas no meio rural. Dissertação. Caruaru. PE, 2011.

FIGUEIREDO. Kattia de Jesus Amin Athayde. Programa Ensino Médio Inovador ProEMI: o que revelam as intenções de melhoria do ensino médio no Brasil - o caso do Distrito Federal. Tese. Brasília, 2015.

GOMES, Maria das Graças Correia. Expressões concretas do programa ensino médio inovador (PROEMI) nas escolas públicas estaduais da mata sul de Pernambuco. Tese. Recife, 2018.

GOMES, Sandra Cristina Andrade Almeida. O Programa Ensino Médio Inovador (PROEMI) e a formação política de jovens na escola pública. Dissertação. Brasília, 2016.

GOMES, Tânia Castro. A Educação Integral e o Programa Ensino Médio Inovador - Proemi: singularidades desta política em uma escola estadual. Dissertação. Santarém, Pará, 2017.

MATOS. Wanda Mara Meguins. Análise do Programa Ensino Médio Inovador no Estado do Amapá no Período de 2010 a 2014. Dissertação. Belém, Pará, 2015

MOFACTO, Elizabete Santos. Curso de Formação "Gestão Escolar para Resultados": Uma Análise à Luz da Experiência da Implementação do Programa Ensino Médio Inovador em Conjunto com o Projeto Jovem de Futuro. Dissertação. Juiz de Fora, MG, 2014.

NARDOTO. Claudia de Souza. Programa Ensino Médio Inovador no Espírito Santo: Mudança ou Continuidade nas Políticas do Ensino Médio. Dissertação. Juiz de Fora, MG, 2015

PEREIRA, Ricardo Inocêncio. Redesenho curricular no programa ensino médio inovador: recontextualizações da política. Dissertação. Blumenau, SC, 2017.

SANTOS. Waneide Ferreira dos. O Programa Ensino Médio Inovador (Proemi) na Rede Estadual de Ensino de Mato Grosso do Sul (2007-2011). Dissertação. Campo Grande, MS, 2016 